\title{
IsoStar Program Suite for Studies of Noncovalent Interactions in Crystals of Chemical Compounds
}

\author{
Alexander S. Novikov ${ }^{1,2}$ (D) \\ 1 Institute of Chemistry, Saint Petersburg State University, Universitetskaya Nab., 7/9, \\ 199034 Saint Petersburg, Russia; a.s.novikov@spbu.ru \\ 2 Infochemistry Scientific Center, ITMO University, Kronverksky Pr., 49, Bldg. A, \\ 197101 Saint Petersburg, Russia
}

Citation: Novikov, A.S. IsoStar Program Suite for Studies of Noncovalent Interactions in Crystals of Chemical Compounds. Crystals 2021, 11, 162. https://doi.org/ $10.3390 /$ cryst 11020162

Academic Editor: Ana M. Garcia-Deibe

Received: 30 January 2021

Accepted: 5 February 2021

Published: 6 February 2021

Publisher's Note: MDPI stays neutral with regard to jurisdictional claims in published maps and institutional affiliations.

Copyright: (C) 2021 by the author. Licensee MDPI, Basel, Switzerland. This article is an open access article distributed under the terms and conditions of the Creative Commons Attribution (CC BY) license (https:// creativecommons.org/licenses/by/ $4.0 /)$.
Abstract: Both Cambridge Crystallographic Data Centre (CCDC) and Protein Data Bank (PDB) provide unique opportunities for finding information about the structures of chemical and biochemical compounds in the solid state. The IsoStar-a knowledge-based library of intermolecular interactions-is a very powerful tool for automatic analysis of a large amount of data from these databases. The IsoStar program suite could help chemists in understanding of probability of occurrence (frequencies) and spatial characteristics (directionalities) of noncovalent contacts (including hydrogen, halogen, and chalcogen bonds, as well as interactions involving $\pi$-systems) between pairs of chemical functional groups; this web application may also be useful for crystal engineers, crystallographers, medicinal chemists, and researchers in fields of computational chemistry and molecular modeling.

Keywords: IsoStar; Cambridge Structural Database; Protein Data Bank; noncovalent interactions

Obviously, the most accurate and objective idea about the structure of chemical compounds in the solid state can be obtained using X-ray crystallography. To date, there are two most extensive online databases on the structure of chemical compounds: Cambridge Crystallographic Data Centre (CCDC, https: / / www.ccdc.cam.ac.uk) and Protein Data Bank (PDB, http:/ / www.wwpdb.org). The CCDC is a crystallographic organization focused on small molecule crystal structures (mainly organic and organometallic compounds), whereas PDB is a database for the three-dimensional structural data of large biological molecules, such as proteins and nucleic acids. Both these databases contain almost unlimited information about the different kinds of noncovalent contacts (including hydrogen, halogen, and chalcogen bonds, as well as interactions involving $\pi$-systems) between atoms and functional groups, and this information could be potentially ultimately interesting for crystal engineers, crystallographers, medicinal chemists, and researchers in fields of computational chemistry and molecular modelling. Unfortunately, manual extraction of the information about the noncovalent contacts from these databases could be very time consuming and subjective.

However, currently there is a brilliant automatic web application for these purposesIsoStar program suite (https:/ / isostar.ccdc.cam.ac.uk/html/isostar.html) [1,2] (Figure 1). Crystallographic information in IsoStar is presented in the form of three-dimensional scatterplots, which could be future converted to contoured density surfaces. Each scatterplot constructed based on the CCDC or PDB search for weak (long) contacts between a pair of functional groups $X$ and $Y$ and demonstrates the experimentally observed distribution of X (contact group) around Y (central group). Such scatterplots provide ideas about the probability of occurrence (frequencies) and spatial characteristics (directionalities) of noncovalent contacts between pairs of chemical functional groups (e.g., C, N, O, S, Si, P, $\mathrm{Se}$, or $\mathrm{H}$ atom, hydrophobic groups like $\mathrm{Me}$ or $\mathrm{Ph}$, halogen atoms, and amino acids). The IsoStar program suite also provide huge statistical information (e.g., the number of crystal 
structures that have both the central and contact groups present, the number of crystal structures in which the central group and contact group form a contact with distance less than the sum of van der Waals radii).

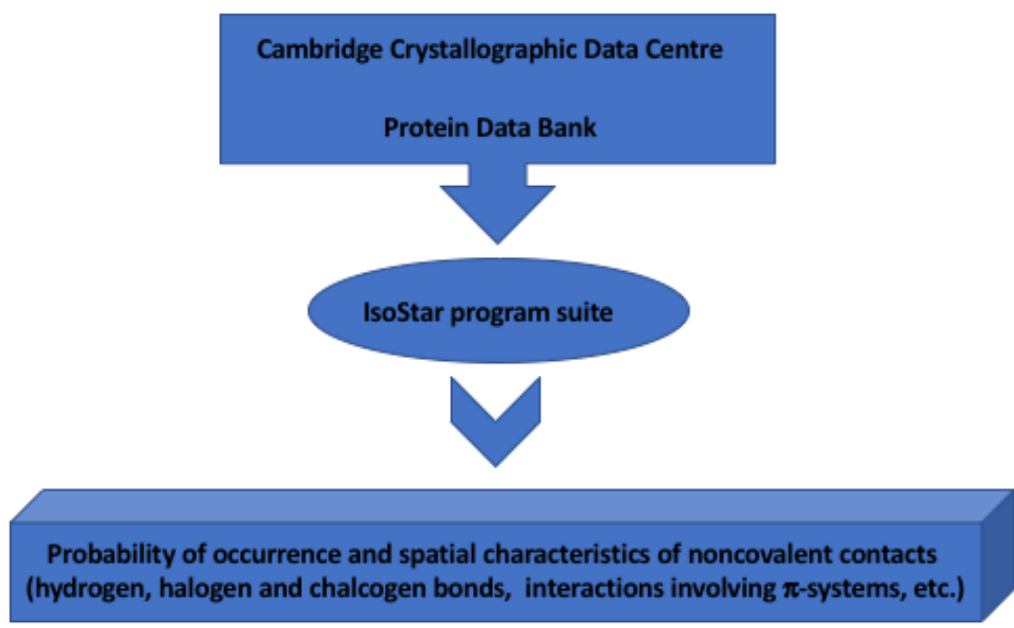

Figure 1. IsoStar program suite-an automatic web application for studies of noncovalent interactions in crystals of chemical compounds.

Inspection of the literature data reveals that the IsoStar program suite could be successfully used for studies of extended supramolecular architectures of co-crystals (up to four- and five-component assemblies) [3], smart and predictable design of molecular crystals via tunable site-specific intermolecular interactions, which provide hierarchical self-assembly [4-6], screening of metal-organic frameworks for materials discovery [7], and density functional theory supported analysis to assess the utility of $\sigma$ - and $\pi$-hole interactions for crystal engineering [8].

Thus, I call the scientific community to pay attention to this useful tool for studying noncovalent interactions in the solid phase and widely use it in daily research work.

Funding: This research received no external funding.

Conflicts of Interest: The author declares no conflict of interest.

\section{References}

1. Bruno, I.J.; Cole, J.C.; Lommerse, J.P.M.; Rowland, R.S.; Taylor, R.; Verdonk, M.L. IsoStar: A Library of Information About Nonbonded Interactions. J. Comput. Aided Mol. Des. 1997, 11, 525-537. [CrossRef] [PubMed]

2. Battle, G.M.; Allen, F.H. Learning about Intermolecular Interactions from the Cambridge Structural Database. J. Chem. Educ. 2012, 89, 38-44. [CrossRef]

3. Aakeröy, C.B.; Sinha, A.S. Chapter 1: Co-crystals: Introduction and Scope. In Co-crystals: Preparation, Characterization and Applications; Aakeröy, C.B., Sinha, A.S., Eds.; The Royal Society of Chemistry: London, UK, 2018; pp. 1-32. [CrossRef]

4. Sinha, A.S.; Aakeröy, C.B. Design of Molecular Crystals Supramolecular Synthons. In Comprehensive Supramolecular Chemistry II; Elsevier: Amsterdam, The Netherlands, 2017; pp. 3-24. [CrossRef]

5. Corpinot, M.K.; Bučar, D.-K. A Practical Guide to the Design of Molecular Crystals. Cryst. Growth Des. 2019, 19, 1426-1453. [CrossRef]

6. Vologzhanina, A.V. Intermolecular Interactions in Functional Crystalline Materials: From Data to Knowledge. Crystals 2019, 9, 478. [CrossRef]

7. Moghadam, P.Z.; Li, A.; Wiggin, S.B.; Tao, A.; Maloney, A.G.P.; Wood, P.A.; Ward, S.C.; Fairen-Jimenez, D. Development of a Cambridge Structural Database Subset: A Collection of Metal-Organic Frameworks for Past, Present, and Future. Chem. Mater. 2017, 29, 2618-2625. [CrossRef]

8. Mooibroek, T.J. DFT and IsoStar Analyses to Assess the Utility of $\sigma$ - and $\pi$-Hole Interactions for Crystal Engineering. ChemPhysChem 2021, 22, 141-153. [CrossRef] [PubMed] 